who inaugurated and maintain the present system of discipline will find fewer thorns in their tutelary path, and give more satisfaction to the taxpaying parents who support the educational institutions.

A LOVER OF CHILDREN."'

This lady, signed "A Lover of Children," makes some happy hits. In the matter of employing teachers, too often teachers are employed who are physical wrecks, this being done from a charitable standpoint. I have known teachers in our common schools who were expectorating large quantities of tubercle every day-spit it upon the floor to dry, of course, and, when dry, to be driven into the air of the schoolroom by every movement of the scholars and every puff of the air. Teachers should be sound in body and mind, and should be employed because they love the work and love children.

COUGH IN ITS RELATIONS TO MORBID STATES OF THE NASAL PASSAGES.

Read in the Section of Laryngology and Otology, at the Fortieth An. nual Meeting of the American Medical Association, June, I889.

BY J. E. SCHADLE, M.D., OF ST. PAUL, MINN.

The syptomatology of morbid processes seldom presents a more perplexing subject for analysis as to its primary cause than that of cough. A chronic cough which will not yield to ordinary methods of treatment and whose ultimate significance is sometimes difficult to understand, is calculated as much as any other single condition to establish in the mind of the sufferer extreme anxiety. This is not strange when it is remembered that we have in it one of the premonitory symptoms of consumption.

It is only from a comprehensive knowledge of all its pathological connections that reliable differentiations can be made in consideration of the primary sources of cough. The peculiar phenomenal sounds characterizing some varieties of cough may aid materially in determining the nature and location of the disease on which its origin depends; but a correct diagnosis from such a basis of investigation cannot always be relied upon; a more extensive research is required.

A series of observations, strengthened by those of other laryngologists, confirms me in the conviction that not enough attention is given to interrogations of the nasal passages when cases of cough present themselves. An important interest belongs to this subject, especially in its practical relations to morbid states of the nasal cavities.

Teachers of rational medicine seem to lose sight of the essential office of the nose as it presides over the act of respiration and that an abnormality of its structures may either directly or sympathetically interrupt the physiological processes of the organs which come under its domain. Experi- ence bears me out in the statement that in conditions where specific organic changes of the lungs are not manifest, a cough spasmodic in character, accompanied or not by temporary alterations of the voice or of the function of respiration, is frequently, if not invariably, of nasal origin. To practically demonstrate the importance of this statement, I will state the histories of several cases which certainly possess the average amount of interest.

Case 1.-Cough due to posterior hypertrophies of the inferior turbinated bones.

$\mathrm{F}$, a young woman, eighteen years of age, came to me ten months ago, for advice concerning a distressing cough which had been troubling her for more than nine years. She stated that during this time all sorts of cough mixtures had been prescribed by different physicians but without affording her permanent relief. The cough was paroxysmal and varied but little during any part of the year. If anything exerted an influence, she thought it was a moist condition of the atmosphere as at such times the seizures were harder and more prolonged. Unattended by expectorations the cough was dry and irritative and came on most intensely at the hours of retiring and rising, particularly the former. Sometimes after assuming the recumbent posture it became more severe, the attacks usually lasting an hour or more. The voice, especially in the evenings, was hoarse.

As to the subjective features of her complaint, she directed my attention to the laryngo-bronchial region where the sensation giving rise to the cough was located. It was a feeling of pronounced irritation resembling very much that produced by the presence of a foreign body requiring expulsion from these parts. In connection with this expression of the disorder, a stopped-up feeling of the nasal chambers was complained of as producing considerable discomfort.

Noticeable among other symptoms was a choreaform disturbance of some of the muscles of the face, which became more pronounced in their convulsive movements under the influence of fear, such as is occasionally created by the presence of surgical instruments used in an examination. The neurotic diathesis evidently was inherited from the father who was himself afflicted with nervous irritability, shown by his uncommon susceptibility to influences peculiar to such a condition. An undue amount of hyperæsthesia was present in the parts as was indicated by sneezing and coughing when pressure was exerted by the operating instrument.

The entire intra-nasal mucous lining was catarrhally affected. It was intensely red and threw off great quantities of serous fluid, thus occasioning a troublesome symptom. The mucous membrane was also very sensitive to the action of local causes of irritation. The use of a probe 
over its surface soon was followed by so-called erectile swellings of the parts touched.

Posterior inspection of the nasal fossæ revealed neoplastic changes of the inferior turbinated bones. The redundant tissue which occupied about onethird of the length of each bone consisted of soft, irregularly shaped growths, the size of an ordinary mulberry. The lumen of the lower meatus was considerably lessened by the condition. The larynx presented no abnormal changes apart from a deep redness and marked infiltration of the subglottic mucous membrane, which condition was limited to this region. Applications of a solution of chloride of zinc to the affected subglottic tissues and a correction of the deformed septum with a Bosworth saw soon yielded entire relief.

The sensitive nervous organization of the patient and the marked morbid changes discovered in the nasal chambers, furnished a clew to the cause of the cough.

The posterior hypertrophies were removed with a snare and the rhinal inflammation reduced by the use simply of antiseptic sprays. To overcome the nervous excitability, the remedies - arsenic, zinc, quinine and strychnine were employed. Under the above management the cough soon disappeared and has remained so ever since.

Case 2.-Cough due to a deformity of the sep. tum narium.

During the autumn of 1888 , a man, forty-three years of age, was sent to me for examination on account of a cough which, he said, fifteen years before had come on without an apparent reason, and which year by year had gradually grown worse. He gave no evidences of tubercular disease either by his own or that of his family history. Generally he was in the enjoyment of good health and regularly followed his vocation as an accountant for a railroad corporation. The cough was spasmodic and often quite violent. Fatigue and active physical exercise had a tendency to bring on the attacks. Unlike the case just cited he was never troubled with the cough after having retired for the night. Usually in the mornings whilst in the act of dressing himself he had a seizure. One of the initial symptoms of a paroxysm was the sensation of a worm crawling through the tissues of the larynx. He also complained of occlusion of the left nostril, which on examination was found to contain a tumor of the septum narium consisting of cartilage and bone. The right nasal chamber, the post-nasal space and the pharynx did not seem to suffer from the obstructed state of the left side of the nose as is commonly the case under such circumstances. Aside from this, the family history contained nothing of special importance.

An examination of the larynx showed thickening of the mucous membrane of the interarytenoid space. The aro and naso-pharyngeal mucous membrane was but slightly altered in its normal appearances. A few chronically enlarged follicles surrounded here and there by hyperæmic patches were observable.

Case 3.-Cough due to chronic nasal catarrh occurring in a subject predisposed to consumption. About one year ago a woman, 25 years of age, medium size, light complexion, came to me through the advice of her medical attendant, complaining of a harassing cough which began six months previously. The cough was accompanied by muco-purulent expectorations. Decided anæmia and loss of flesh were showing. themselves; the appetite was poor, the bowels irregular and the menstrual function deranged. In connection with the symptoms of cough she also complained of an excessive chronic discharge from the nasal passages, which had been troubling her for a few months prior to the onset of the cough. The cause of the rhinal disorder she attributed to a neglected cold in the head. The family history was very discouraging, as she stated that one parent and several sisters had died from tubercular disease. A physical examination of the chest gave no evidence of a coexisting lung disease. By the use of the laryngoscope a catarrhal change of the larynx, such as is sometimes initiative of tubercular laryngitis, was discovered. The mucous membrane was hyperæmic; the arytenoid cartilages were swollen and intensely red; the vocal bands sympathized but little with the morbid process; beyond them in the trachea no change of structure was perceptible; the voice was impaired in both quality and strength ; some pain was experienced on swallowing water or food. The rhinoscope brought to light a well-seated chronic rhinal inflammation involving the whole membrane covering the intra-nasal fossæ. The mucous membrane was purple-red and swollen, and was actively engaged in throwing off the offensive secretions of which mention has been made. Whilst a quantity of purulent material was blown from the nose, much of it found its way into the throat from behind the palate. It at first seemed as though the patient was suffering from laryngeal phthisis, an opinion entertained by her former physician; but as there were no signs indicating pulmonary trouble, it appeared clear that the cough and laryngitis were secondary elements in the case; they were a consequence of the pre-existing catarrhal disease of the nasal passages.

The treatment pursued with a view to eradicate the cough consisted in an attempt to remove the catarrhal affection of the nose and throat, and to tone up the general system of the patient. The former end was accomplished by the local applications of antiseptic and alterative agents, the latter by the administration of the syrup of the iodide of iron in full doses. As soon as an impression both locally and constitutionally was made the cough ceased. 
Repeated observations on the peculiar behavior of nasal disorders add testimony to the fact that those diseases of the nose which predispose to the establishment of reflex disturbances are the morbid processes which give rise to cough when it is thus pathologically related.

A study of reflex neuroses during recent years has developed a fertile field for the investigation of not a few phenomenal symptoms of disease whose etiology hitherto remained obscure. It is nowadays a conclusive observation that with a knowledge of nasal reflexes in their pathological aspects a way has been opened for a better understanding of the cause and treatment of a certain form of so-called nervous headache. An inquiry into the state of the nose not infrequently reveals a contributory factor to the production of spasmodic asthma, whose cure becomes expedient by a removal of the nasal difficulty.

The extraordinary reflex symptoms of hay fever which give character to the affection, it is now well known, have their focus of origin seated in a morbid state of the intra-nasal cavities. Local choreaform movements of the muscles of the soft palate, of the face, or of the larynx, are sometimes traceable to intra-nasal irritation.

The "pathological nasal reflexes" described by Dr. John N. Mackenzie are thus seen to have a special importance attached to themselves, which I am sure should merit the attention of all intelligent physicians. To this category belongs a spasmodic cough whose cause is located in a morbid state of the nasal passages, and whose existence remains permanent until the intra-nasal lesion is got rid of.

Through the sympathetic nervous influence exerted by the presence of diseases of the cavities of the nose more or less irritation of the peripheral nervous filaments of the laryngo-bronchial mucous membrane takes place, whereby cough is induced.

"Recurrent laryngitis" attended by cough Dr. Ingalls attributes to a coexisting nasal catarrh or obstruction, and maintains that a cure is performed by giving proper attention to the treatment of the nasal passages.

In the classical writings of Dr. John N. Mackenzie we find it said that "various neuralgic conditions of the branches of the fifth and other nerves - cough, asthma, vertigo, nightmare, diseased states of the eye, ear, larynx and bronchial tubes - have been mitigated or known to disappear with a cure of the nasal affection."

Paresis of the vaso-motor blood-vessels of the nasal mucous membrane, resulting from neglected attacks of acute rhinitis or local irritation from a deformed septum or morbid growth plays unquestionably a conspicuous part in bringing about secondary effects of the larynx or bronchial tubes accompanied with cough and other serious consequences.
Referring to this subject a few years ago, Dr. Bosworth said: "We often regard a laryngitis and bronchitis as the extension of a catarrhal process from the nasal membrane. That such is the case I do not believe. There is no continuity of tissue. That this is the true view is well shown by the fact of our utter failure for many years to treat successfully catarrhal disease in the larynx and trachea by local application, and by our striking success in curing such diseases by removing diseased conditions in the nose, to the exclusion of any local measures whatever directed to the passages below." Further on he says: "Vaso-motor paresis of the blood-vessels of the nose constituting inflammation is liable to be followed by vaso-motor paresis in the larynx, trachea and bronchi."

The treatment of a chronic cough dependent on intra-nasal disease at once becomes apparent. By following the precepts of the quotation from remarks of the President of this Section, "that the laryngologist of the future must be more the rhinologist, and the rhinologist more the surgeon than the physician," a correct method of treatment of this symptom, as it occurs in connection with morbid states of the nasal passages, is usually afforded.

\section{EFFECT OF NATURAL GAS UPON UPPER AIR PASSAGES.}

Read in the Section of Laryngology and Otology, at the Fortieth Annual Meeting of the American Medical Association, June, 1889 .

BY D. M. RANKIN, A.M., M.D.,

OF ALLEGHENY, PA.

In 1883 , when natural gas was first introduced into Pittsburgh as a fuel, loud and many were the complaints that the heat it produced had the effect of making the atmosphere too dry for breathing purposes (not taking into consideration this new and untamed fluid, as to its noxious and combustible qualities) that it irritated the nose and throat.

So great was the complaint at first that a great many persons had it removed from their dwelling houses, but ingenuity often conquers a great many difficulties, and it certainly did in this case. The dryness of the atmosphere produced by the heat of the gas was obviated by kettles filled with water, hung over the fireplaces in which the gas was burning, the water in the kettles would become sufficiently heated to generate steam enough to neutralize the dryness produced by combustion of the natural gas. This dryness of the atmosphere was not an imaginary thing, because even after burning the natural gas in an open grate for a few minutes, the cracking and opening of the glued joints of the furniture of that room could be distinctly heard and seen. Before the plan of moistening the air was introduced, a large amount of the finest and most expensive furniture, such 